\title{
Two Emission Reduction Scenarios of Single Carbon Tax or Combined With Carbon Trading and Their Impacts on National Economics
}

\author{
Zhiqiang Wang \\ School of Management Science and Engineering, Dongbei University of Finance and Economics, Dalian \\ 160022, China
}

School of Economics and Management, Zhejiang A \& F University, Lin'an 311300, China

Jun Zhou*

School of Economics and Management, Zhejiang A \& F University, Lin'an 311300, China

*Corresponding author: Jun Zhou

\begin{abstract}
In response to global climate change, according to the policy attributes of carbon taxes and carbon trading, the paper designs two emission reduction scenarios, single carbon tax and the joint use of carbon tax and carbon trading, and builds the computable general equilibrium (CGE) model to simulate and analyze their impacts on China's economy under three kinds of emission reduction target in two scenarios. The results showed that: the single carbon tax scenarios an produce the negative influence with different degree on both whole economy and 11 major economic sectors; Introduce carbon emissions trading into model, the results shows it will slow down the impact of carbon tax on China's economy and has a positive effect on the low carbon energy sectors. The emission reduction policy of combination of carbon tax and carbon trading are more in line with China's actual condition.
\end{abstract}

KEYWORD: Carbon tax; carbon trading; general equilibrium model; economic impact

\section{INTRODUCTION}

The climate change with the main features of the warming global has become one of the most important challenges facing the world today, and the emission of greenhouse gas which gives priority to carbon dioxide causes global warming. Paris Agreement (2015) specifically called for controlling the global temperature rise of $2^{\circ} \mathrm{C}$ within this century, marking the starting point of global climate order and carbon emission reduction.

Carbon emission reduction is not only a technical problem, but also an economic issue, and it's indispensable to adopting various policy instruments and cooperative mechanism to motivate the greenhouse gas emissions cut. The current environmental policy measures coping with global climate change mainly include two categories: one is traditional 'command and control' means and the other is market based economic instrument. There have certainly been trends among many countries to increasingly rely on economic instrument based upon 'command and control' means. Whether from the perspective of theory or practical problem of environmental management, both the carbon tax method based on Pigou theorem and carbon trading means based on Coase theorem have appealed increased attentions of most governments around the world.

China has exceeded the United States to take the first place in the world in carbon emission, account- ing for about $30 \%$ of the world's emission (Liu hui et al, 2011). As a responsible big country, China is of utmost importance in guiding and facilitating the global cooperation to confront climate change. Furthermore, the implementation of carbon emission reduction is also an inherent requirement of China's changing economic development mode and the vitable choice of realization of socio-economic sustainable development. Facing the dual reduction pressures from international and domestic, China' $\mathrm{s}$ targets for emission reduction will only become higher and higher, and what effective measures China can take to reduct carbon emission is particularly import.

Supply side of carbon trading market mainly includes carbon sink project developer, enterprises and institution with a lower emission reduction cost, etc. Carbon performance buyers mostly are industrialized countries (annex I parties) and emission entity with higher reduction cost. After the Kyoto Protocol, many countries and regions have adopted legislation to implement mandatory emissions trading scheme, and there is also a voluntary market. So, there also have some voluntary buyers such as governments, enterprises, social organizations and individuals who are responsible for the conduct of social responsibility or to prepare for performing carbon trading (Shi min-jun et al, 2013). China's market is a developing market with the structure and mechanism remaining to be perfected. In addition, the market has not yet 
established a carbon trading primary market. so without mandatory policy instruments such as carbon tax, only relying on domestic enterprises, the government, the individual's willingness to buy and foreign carbon market digestion is difficult to promote the rapid development of the domestic carbon market, let alone to realize of future emission reduction targets in China. But whether carbon tax collection or the implementation of carbon emission trading will have a greater impact on the national economy (Gao Pengfei et al, 2002). China's carbon tax conditions are basically ripe and national-wide carbon market is planned to be started in 2017 (Carbon tax research group, 2009), so the study on carbon tax or combined with carbon trading with their impact on national economics has strong practical and theoretical significance.

\section{MODEL HYPOTHESIS}

The main assumptions of the model include the general assumption of the standard CGE model, i.e., the market competition, the enterprise profit maximization, the maximization of consumer utility, and so on. The following highlights some of the special assumptions of the model.

(1)Carbon emissions trading market is closed, the supplier and buyer of carbon emissions are domestic enterprises.
(2)Enterprises can choose carbon trading or carbon tax to achieve emission reduction targets.

(3)The calculation of carbon tax based on $\mathrm{CO}_{2}$ emissions (Carbon tax research group, 2009). This paper assumes that the finished products does not levy carbon tax and only tax on the intermediary inputs with the use of fossil energy. The economic impact of carbon tax is reflected in the rise of the fossil fuels price, which affects the usage of fossil fuels in other sectors of the economy.

\section{PRODUCTION STRUCTURE MODEL}

The model includes 11 production sectors. Department total output are described by using the multilevel mested CES (Constant Elasticity of substitution) production function with variables of labor, capital, energy and other intermediate inputs. In order to explore the substitutability among the energy inputs and the alternative relationship between energy inputs and other elements, the energy inputs are separated from the other intermediate inputs, embedded into nested multilevel structure of the added value production function in the formation of hierarchical structure of various energy inputs, and polymerized with capital to form energy- capital inputs. The study hypothesizes that producer who pursues production under the lowest cost make the optimal portfolio of elements inputs according to the relative price of inputs.

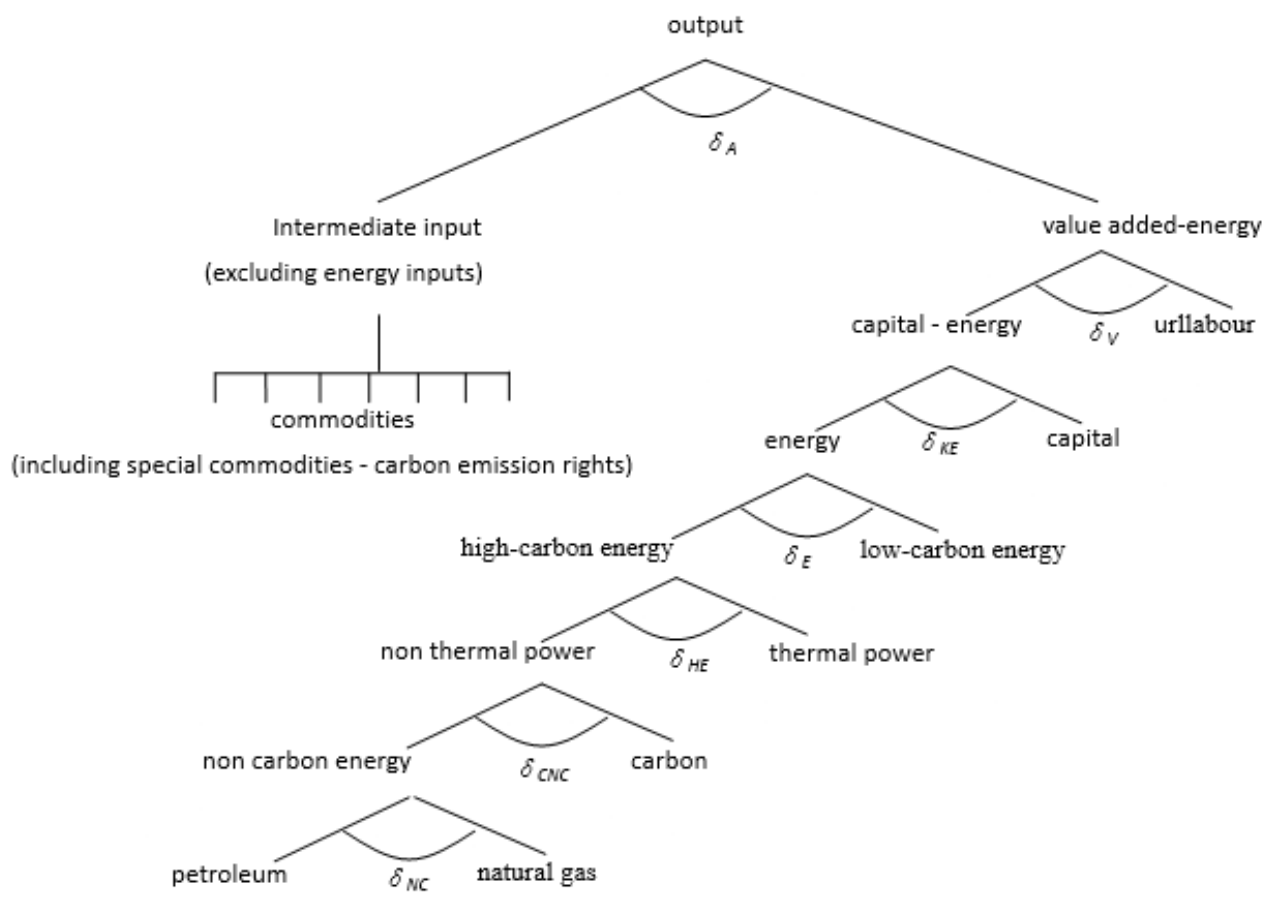

Fig. 1 production structure 


\section{CARBON TRADING MODE DESIGN}

Carbon trading mode added a special commodity, emission permits trade of carbon, into 'acctivitiescommodities' module. In this model, the carbon trading market is designed as a closed model with all the carbon trading completed among the domestic enterprises (Chen xing, 2012). In the future research the carbon trading market will be designed as an open model. The research assumes that the supply side of carbon emissions in the model are low carbon energy sectors without considering other supplies. As we know, in reality, there are a lot of other supplies of carbon emissions, like forest carbon sink. Due to various technical and practical reasons, such as the supply of forest carbon sink have many technical and standard barriers, and the data are difficult to obtain, this model is simplified and only consider low carbon energy sectors as the supply of carbon emissions. This process does not change the qualitative impact of carbon trading on the national economy, and the most likely outcome may weaken the economic impact of the forestry sector.

In this paper, the carbon tax collection method is to levy carbon tax on fossil energy products of energy sectors, So in this model the buyers of the carbon emission permit are only the fossil energy sectors, and the fossil energy production enterprise buys the carbon emission permit as the middle input causing the price change of the fossil energy products. Fossil energy production enterprises can achieve emission reduction targets by paying the carbon tax or the purchase of carbon emission permits.

\section{CARBON TAX DESIGN}

Fossil energy final investment and consumption demand for energy of total demand is relatively small, so this paper assumes that carbon tax impose on fossil energy intermediate input with the tax basis of $\mathrm{CO}_{2}$ emissions, not on the final products. Specific carbon tax design using the following equation:

$$
\begin{array}{ll}
\text { CTAX }{ }_{j}=t c \cdot \sum_{i} E_{i, j} \cdot \theta_{j} & j=\text { coal, oil, gas } \\
\text { CTAX }{ }_{i}=t c \cdot \sum_{j}^{j} E_{i, j} \cdot \theta_{i} & j=\text { coal,oil, gas } \\
\text { TCTAX }=\sum_{i} \text { CTAX }_{i} &
\end{array}
$$

Where CTAX is the amount of carbon tax on fossil energy intermediate input,, CTAX $X_{i}$ is the amount of carbon tax on the sector $\mathrm{i}$, TCTAX is the total carbon tax, $t c$ is tax rate of carbon tax, meaning tax amount on $\mathrm{CO}_{2}$ emissions per ton, $\theta$ is emission coefficient of three kinds of energy, including coal, oil and gas, $E_{i, j}$ represents the energy consumption of each sector.

After getting the carbon tax on fossil energy, it can figure out ad valorem rate of duty, that is, the ratio of the carbon tax amount of a kind of fossil energy and the value of its domestic demand. The formula for calculation is as follows:

$$
t_{c j}=\frac{C T A X_{j}}{P Q_{j} \cdot Q Q_{j}}
$$

Thus, demand price of fossil energy will be changed to $\left(1+t_{c j}\right) P Q_{j}$, and will directly affect the use cost of fossil energy input of the production fuction's 4th level, high carbon energy layer. Meanwhile, due to carbon tax, the government's total revenue will also increase. The formula for calculation is as follows:

$$
Y G T=\sum_{i} G I N D T A X_{i}+\sum_{i} G_{T R I F M}+G E T A X+G H T A X+G W Y+T C T A X ;
$$

\section{MODEL DATA SOURCE}

\subsection{Compilation of SAM table}

The main data in the SAM table are from the latest release of the input output table (2007). Sectoral data of micro social accounting matrix are mainly from input-output table, and consolidation data table in accordance with the dividing standard of 11 sectors including coal, petroleum, natural gas, thermal power (above four departments belong to high carbon energy) and other power (low carbon energy), agriculture, light industry, heavy industry, construction, transportation and warehousing industry and services. The power sectors are divided into high carbon energy sectors and low carbon energy sectors, the split ratio of the electricity sector in accordance with the production proportion between thermal power and other power in the 2007 China Energy Statistical Yearbook, and details are as follows: thermal power accounted for $83.06 \%$, nuclear power and other power supply were $16.94 \%$. According to the 2007 energy consumption structure, oil accounted for $19.7 \%$ of total energy consumption and natural gas accounted for $3.50 \%$. Then on the basis of the proportion of consumption, the datas of the inputoutput table are divided into the oil sector and the natural gas sector. In addition, the data about employment, energy, taxes, savings, transfer payments, trade surplus etc. are collected from reports in the China Labor Statistical Yearbook, China energy statistical yearbook, the almanac of China taxation, almanac of China's finance, the Customs Statistics Yearbook, the traditional Chinese Design Yearbook and other publications and the national Bureau of statistics released (Li yuan-long et al, 2011). 


\subsection{Set of alternative elastic coefficients}

The elasticity coefficient of substitution for production function and trade function in CGE model are generally obtained by economic measurement or consulting related experts. At present, many domestic and foreign scholars have conducted a lot of research in related fields and have achieved fruitful results, such as Tan and Burniaux \& Truong. (2002), Zhai \& Hertel (2005), he Ju Huang (2002), Zheng
Yuyu and Ming Tai fan (1999), Wang (2003), Ma Shiguo (2005) show East (2008), Xuan Xiaowei (1998) (Mustafa H.Babiker et al, 2003) (Wang Can et al, 2005) (Meng Xiaolian et al, 2005) (Lan W.H Parry. 2003) (He Juhuang et al, 2002) (Sebastien Dessus et al, 2003). This study comprehensively considers the previous scholars' research results, and the related numerical values are shown in Table 1:

Table 1 substitution elasticity of production function

\begin{tabular}{|c|c|c|c|c|c|c|c|c|c|c|c|}
\hline \multirow{2}{*}{ type } & \multirow{2}{*}{ agriculture } & \multirow{2}{*}{$\begin{array}{l}\text { heavy in- } \\
\text { dustry }\end{array}$} & \multirow{2}{*}{$\begin{array}{l}\text { light in- } \\
\text { dustry }\end{array}$} & \multirow{2}{*}{ construction } & \multirow{2}{*}{ traffic } & \multirow{2}{*}{ service } & \multicolumn{4}{|c|}{ high-carbon energy } & \multirow{2}{*}{ 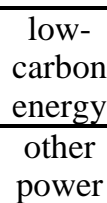 } \\
\hline & & & & & & & coal & $\begin{array}{c}\text { fossil } \\
\text { oil }\end{array}$ & $\begin{array}{c}\text { natural } \\
\text { gas }\end{array}$ & $\begin{array}{c}\text { thermal } \\
\text { power }\end{array}$ & \\
\hline$\delta A$ & 0.3 & 0.3 & 0.3 & 0.3 & 0.3 & 0.3 & 0.3 & 0.3 & 0.3 & 0.3 & 0.3 \\
\hline$\delta V$ & 0.8 & 0.8 & 0.8 & 0.8 & 0.8 & 0.8 & 0.6 & 0.8 & 0.8 & 0.8 & 0.8 \\
\hline$\delta K E$ & 0.6 & 0.6 & 0.6 & 0.6 & 0.6 & 0.6 & 0.6 & 0.6 & 0.6 & 0.6 & 0.6 \\
\hline $\begin{array}{l}\delta E \\
\end{array}$ & 0.9 & 0.9 & 0.9 & 0.9 & 0.9 & 0.9 & 0.9 & 0.9 & 0.9 & 0.9 & 0.9 \\
\hline$\delta H E$ & 0.7 & 0.7 & 0.7 & 0.7 & 0.7 & 0.7 & 0.3 & 0.3 & 0.3 & 0.3 & 0.3 \\
\hline$\overline{\delta C N C}$ & 0.5 & 0.5 & 0.5 & 0.5 & 0.5 & 0.5 & 0.2 & 0.2 & 0.2 & 0.2 & 0.2 \\
\hline$\delta N C$ & 0.9 & 0.9 & 0.9 & 0.9 & 0.9 & 0.9 & 0.9 & 0.9 & 0.9 & 0.9 & 0.9 \\
\hline
\end{tabular}

\section{3 $\mathrm{CO}_{2}$ emission coefficient}

According to the statistics released by the International Energy Agency, $\mathrm{CO}_{2}$ emission coefficient are calculated by dividing $\mathrm{CO}_{2}$ emissions amount by the actual consumption of three kinds of fossil energy in China. The specific calculation results are shown in Table 2:

Table 2 CO2 emission coefficient Unit: tons / million \begin{tabular}{|l|l|l|l|}
\hline type & coal & fossil oil & natural gas \\
\hline $\mathrm{CO}_{2}$ mission coefficient & 41.01415 & 3.05803 & 4.07095 \\
\hline
\end{tabular}

\section{RESULT ANALYSIS}

This paper sets up two simulation scenarios. S1 analyse the impact on the national economy with a single way of carbon tax, and S2 is the joint use of carbon tax and carbon trading,two emission reduction means. The following table describes the impact of the two scenarios on the national economy under 3 different emission reduction targets.

Table 3 the impact of the two scenarios on the national economy under different emission reduction targets Unit: \%

\begin{tabular}{|c|c|c|c|c|c|c|}
\hline scenario & \multicolumn{3}{|c|}{ S1 } & \multicolumn{3}{c|}{ S2 } \\
\hline emission targets & 5 & 10 & 20 & 5 & 10 & 20 \\
\hline GDP & -0.087 & -0.143 & -0.277 & -0.079 & -0.129 & -0.213 \\
\hline agriculture & -0.007 & -0.054 & -0.078 & 0.000 & -0.049 & -0.063 \\
\hline light industry & -0.017 & -0.053 & -0.177 & -0.016 & -0.044 & -0.153 \\
\hline heavy industry & -0.093 & -0.156 & -0.293 & -0.088 & -0.146 & -0.285 \\
\hline construction & -0.097 & -0.166 & -0.288 & -0.083 & -0.153 & -0.280 \\
\hline traffic & -0.107 & -0.176 & -0.301 & -0.099 & -0.159 & -0.293 \\
\hline service & -0.013 & -0.043 & -0.067 & -0.011 & -0.041 & -0.063 \\
\hline coal & -0.168 & -0.253 & -0.397 & -0.159 & -0.239 & -0.373 \\
\hline fossil oil & -0.156 & -0.204 & -0.334 & -0.149 & -0.199 & -0.313 \\
\hline natural gas & -0.117 & -0.192 & -0.307 & -0.109 & -0.184 & -0.299 \\
\hline thermal power & -0.158 & -0.242 & -0.378 & -0.149 & -0.232 & -0.369 \\
\hline other power & -0.001 & -0.003 & -0.007 & 0.002 & 0.015 & 0.023 \\
\hline
\end{tabular}

From the table 3, we can observe that under three emission reduction targets, there have a different degree of negative impact on the entire economy and the 11 major economic sectors in S1 scenario which means that carbon tax adversely affect the China's national economic growth and especially have most significant influence on fossil energy enterprise. This is mainly due to the indirect tax system in China. Carbon tax are levied mainly in the production link of energy, so the fossil energy industry are the 
direct object of the carbon tax collection. Direct taxation on the fossil energy products of fossil energy enterprise, the impact of carbon tax on fossil energy enterprise will directly lead to the rise in energy prices, and indirectly influence the other highly fueldependent industries and cause a rise in their products prices.

In S2 scenario, the joint use of carbon tax and carbon trading, negative impact on the entire economy and sectors are less than in S1 scenario. Such as setting emission reduction targets for 20\%, in S1 GDP will be reduced by $0.277 \%$, while in S2 GDP decline only $0.213 \%$. Visiblely, the introduction of carbon emissions trading mechanism, will slow down the negative impact of a single mandatory carbon tax on the overall national economy.

Furthermore, in S2 scenario there have a positive impact on the low carbon energy sectors under all emission reduction targets. This is due to the carbon emissions trading making the low carbon energy sectors obtaining additional economic benefits. And the introduction of carbon trading mechanism is also conducive to highly energy-dependent enterprise saling the amount of $\mathrm{CO}_{2}$ emission reduction bringed by technological innovation to reduce the cost caused by $\mathrm{CO}_{2}$ emission.

\section{CONCLUSIONS}

Due to the new start of global climate order, China should consider how to adopt effectively climate policy reducing carbon emissions with minimizing the negative impact on economy and encouraging the development of low-carbon energy sectors. The paper designs two emission reduction scenarios, single carbon tax and the joint use of carbon tax and carbon trading, and builds the computable general equilibrium (CGE) model to simulate and analyze their impacts on China's economy under three kinds of emission reduction target in two scenarios. The main conclusions are as follows:

(1)The main source of global greenhouse gas emissions is burning fossil fuels. Transformation and upgrading of the energy sector is the core of reducing greenhouse gas emissions. Research shows that the two emission reduction scenarios will have incentive effect on the high-carbon energy sectors.

(2)Once the conditions are ripe, carbon tax should be collected in the whole country as soon as possible with the construction of carbon emissions trading market. The introduction of carbon emissions trading mechanism can slow down the negative impact of a single mandatory carbon tax on the overall national economy and bring positive impacts on low-carbon energy sectors. Carbon trading is also conducive to the transformation and upgrading of traditional energy enterprises and optimizing the energy structure. Visiblely, carbon tax combined with carbon trading is more suitable for China's national conditions to cut emissions.

(3)The government should encourage enterprises to actively introduce advanced emission reduction technology and increase the investment in the development and research of emission reduction technology. And government also ought to introduce relevant policies to encourage the supply of carbon sequestration, including forest carbon sink, as soon as possible to achieve emissions reduction status with carbon tax and carbon trading combination.

\section{ACKNOWLEDGEMENTS}

This work was financially supported by the Ministry of education of Humanities and Social Science project (11YJC790198) and natural science foundation of Zhejiang Province, China (Q12G030048).

\section{REFERENCES}

Gao Pengfei, Chen Wenying. Carbon tax and carbon emission [J]. Journal of Tsinghua University (science and technology), 2002, 42(10): 1335-1338.

Carbon tax research group, China's introduction of carbon tax framework design [J]. China Finance, 2009(20):38-40.

Chen xing. Equilibrium Analysis of the Transaction about Emission Rights based on Cobweb Model[J]. Energy Research and Management, 2012(4):15-19.

[EB/OL].2009-12-20[2014-01-

01].http://finance.sina.com.cn/j/20091220/08217128048.Sht ml q-pf-to=pcq q. c2c.

He Juhuang, Shen Keting, Xu Gao. Age of technology and economy CGE model [J]. The journal of quantitative \& technical economics, 2002, 10:39-47.

Lan W.H Parry. Fiscal Interactions and The Case for Carbon Taxes Overs Grandfathered Carbon Permits[J] .Oxford Review of Economic Policy, 2003,19(3):385.

Liu hui, Fan jie, Guillaume Giroi. Carbon Emission Trend and Green Economy Prospect in China[J]. China Population, Resources and Environment, 2011(S1):151-154.

Li yuan-long, Lu wen-cong. The Economy-wide Rebound Effects of Energy Efficiency Increase in Production [J]. China Population, Resources and Environment, 2011, 21(11):4449.

Meng Xiaolian, Du Kuanqi, Cai Shuqin. Model of [J]. The journal of quantitative \& technical economics, 2005, 22(5):79-88.

Mustafa H.Babiker, Patrick Criqui, A. Denny Ellerman, John M.Reilly, Lauren L. Viguier. Assessing the Impact of Carbon Tax Differentiation in the European Union[J].Environm ental Modeling\&A-ssessment,2003,8(3):187-197.

National Development and Reform Commission Economic Research. A study on the active Fiscal Policy Transformation and the fiscal sustainability[J].Review of Economic Research,2012(2):1-33.

Sebastien Dessus, David O'Connor. Climate Policy without Tears: CGE-Based Ancillary Benefits Estimates for Chile[J].Environmental and Resource Economics, 2003,25(3):287. 
Shi min-jun, Yuan yong-na, Zhou sheng-lü. Carbon tax, capand-trade or mixed policy: Which is better for carbon mitigation? [J]Journal of Management Sciences in China, 2013, 16(9):9-19.

Wang Can, Chen Jining, Zou Ji.the impact of $\mathrm{CO} 2$ emission reduction on the Chinese economy based on the CGE model [J]. Journal of Tsinghua University (science and technology), 2005.45(12): 1621-1624. 